Article

\title{
Anti-Inflammatory Properties and Gut Microbiota Modulation of Porphyra tenera Extracts in Dextran Sodium Sulfate-Induced Colitis in Mice
}

\author{
Jungman Kim ${ }^{1, \dagger}$, Jae Ho Choi ${ }^{2,+}$, Gwangpyo Ko ${ }^{1} \oplus$, Hyejun Jo ${ }^{1}$, Taehwan Oh $^{3}$, Byungjae Ahn ${ }^{3}$ \\ and Tatsuya Unno $1,2, *$ (D) \\ 1 Faculty of Biotechnology, School of Life Sciences, SARI, Jeju National University, Jeju 63243, Korea; \\ kjm5364@gmail.com (J.K.); rhkdvy1004@gmail.com (G.K.); hyejun758@gmail.com (H.J.) \\ 2 Subtropical/Tropical Organism Gene Bank, Jeju National University, Jeju 63243, Korea; \\ jaehochoi78@gmail.com \\ 3 Marine Biotechnology Research Center, Jeonnam Bioindustry Foundation, Wando 59108, Korea; \\ sosoth2@hanmail.net (T.O.); chemeditech@hanmail.net (B.A.) \\ * Correspondence: tatsu@jejunu.ac.kr; Tel.: +82-64-754-3354 \\ + These authors contributed equally to this work.
}

Received: 24 August 2020; Accepted: 7 October 2020; Published: 14 October 2020

\begin{abstract}
Porphyra tenera (PT) is a functional seaweed food that has been reported for health benefits such as antioxidant, immunostimulant, anti-inflammation, and hepatoprotective effects. In this study, we investigated the effect of PT extracts on gut microbiota modulation in colitis-induced mice. The mice experiment was designed as three groups including normal mice (CTL), dextran sodium sulfate (DSS)-fed mice, and DSS plus PT extracts-fed mice (PTE). DSS was administrated through drinking water containing DSS for 1 week, and the PT extract was ingested into the gastrointestinal tract in mice. PT extract ameliorated the decreased body weight and colon length and improved disease activity index and pro-inflammatory cytokine expression. In addition, PT extract significantly shifted the gut microbiota of mice. DSS treatment significantly increased the portion of harmful bacteria (i.e., Helicobacter, Mucipirillum, and Parasutterella) and decreased the butyrate producing bacteria (i.e., Acetatifactor, Alistipes, Oscillibacter, and Clostridium_XIVb). PT extract increased the abundance of genera Clostridium_XIVb and also enriched some of predicted metabolic activities such as glyoxylate cycle, ethylmalonyl-CoA pathway, nitrate reduction, creatinine degradation, and glycine betaine metabolism. These results suggest that PT extract may ameliorate the DSS-induced colitis inflammation through regulating the compositions and functions of gut microbiota in mice.
\end{abstract}

Keywords: Porphyra tenera; colitis; gut microbiota; inflammation

\section{Introduction}

Recent studies have revealed that the balance of the intestinal microbial environment plays an important role in controlling inflammation and oxidative damage in the colon. It has been found that the composition of intestinal micro-organisms and microbial metabolites is significantly altered in inflammatory colitis patients and colitis-induced mouse models [1]. Furthermore, gut microbial diversity is important in linking diet to host physiology and pathology, which is influenced by dietary composition and pattern [2]. The gut microbiota is a complex ecosystem that plays a critical role in regulation of immune system homeostasis. Recent studies showed that gut microbes are related with many diseases such as obesity, type 2 diabetes, non-alcoholic fatty liver disease, cardiovascular disease, nervous system disease, and IBD [3-7]. It has been reported that dysbiosis of gut microbiota exacerbate the development of these diseases. Some studies reported the interaction between the gut bacteria 
and the mucosal immune system that plays an important role in maintaining intestinal health and preventing the development of IBD [8].

Seaweeds are composed of approximately $70 \%$ polysaccharides. Seaweeds contain indigestible dietary fibers for humans and only digested or fermented by intestinal microbes in the large intestine. The final digested products, such as short chain fatty acids, are absorbed to the host's epithelial cells and control the host immune system [9]. Among the edible seaweeds, Porphyra has been a diet consumed in Korea, over a long period of time. The dried form of Porphyra contains approximately $35 \%$ water-soluble polysaccharides, including $10 \%$ porphyran [10]. Many studies have reported that Porphyra tenera (PT) extracts is the rich in total polyphenols and total flavonoids, which have antioxidant and radical scavenging activities [11]. Porphyran, a major component of PT, inhibits ear edema in mice by 2,4,6-trinitrochlorobenzene-induced contact hypersensitivity [12]. The volatile oil of PT, which has a bioactive chemical components and strong antioxidant effect, can be used in the food industry as food additive as well as a cosmetic duet to its antioxidant properties [13]. Mycosporine-like amino acids extracted from PT protect skin from UV irradiation-induced photodamage [14]. Furthermore, PT possesses chemo-preventive effects against diethylnitrosamine-induced hepatocarcinogenesis [15]. Previous studies have reported that PT extracts enhanced the immune response through NF- $\mathrm{kB}$ immunostimulant in macrophage [16]. Furthermore, PT extracts supplementation enhanced immune function by improving natural killer cell activity without adverse effects in healthy adults [17].

Although PT extracts has been reported to exhibit various beneficial effects, its efficacy against inflammatory colitis and gut microbiota dysbiosis has not been investigated. In this study, we evaluated the inhibitory effects of PT extracts on intestinal inflammation and gut microbiota in dextran sulfate sodium (DSS)-induced colitis mice. Administration of DSS induces mucosal damage, which shifts the gut microbiota and brings about changes in cytokine levels and other physical characteristics such as length of intestines and body weight.

\section{Materials and Methods}

\subsection{Preparation of Porphyra tenera (PT) Extracts}

PT extracts used in this study were previously characterized [17]. PT were collected from the coastal area of the island (Soan-do; $38^{\circ} 8^{\prime} 29.36^{\prime \prime} \mathrm{N}, 126^{\circ} 39^{\prime} 22.59^{\prime \prime} \mathrm{E}$ ) in the southern coast of Korea in February and March, 2015 (Figure S1), repeatedly washed with fresh water and then air-dried at $50{ }^{\circ} \mathrm{C}$ for $72 \mathrm{~h}$. Extraction was performed at $80 \pm 2{ }^{\circ} \mathrm{C}$ for $3 \mathrm{~h}$ using $10 \%$ ethanol $(v / v)$. PT extracts was freeze-dried after filtration using a $1 \mu \mathrm{m}$ housing filter. The extract was concentrated to approximately 10-20 Brix at $65-70{ }^{\circ} \mathrm{C}$. The composition of PT extracts and the concentration of porphyra- 334 in PT extracts were described in our previous study [17]. PT extracts was stored at $-20^{\circ} \mathrm{C}$ until used in animal experiment.

\subsection{Determination of Total Polyphenols Content}

Total polyphenol content was measured by Folin-Ciocalteu assay [18]. Sample solution (300 $\mu \mathrm{L})$ was mixed with Folin-Ciocalteau $(160 \mu \mathrm{L})$ and dilution water $(250 \mu \mathrm{L})$ for $5 \mathrm{~min}$. Then, a $10 \%$ sodium carbonate solution $(300 \mu \mathrm{L})$ was added to the reaction and the solution was incubated at room temperature for $30 \mathrm{~min}$. Optical density was determined at $750 \mathrm{~nm}$ using a VERSA max microplate reader (Molecular Device, San Jose, CA, USA). Results were calculated in mg gallic acid equivalent (GAE)/g sample.

\subsection{Determination of 1,1-Diphenyl-2-Picrylhydrazyl (DPPH) Free Radical Scavenging Activity}

Free radical scavenging ability of the PT extracts was evaluated by DPPH radical scavenging assay as previously reported with a minor modification [19]. The $0.1 \mathrm{mM}$ DPPH solution was diluted with $150 \mu \mathrm{L}$ of ethanol and added to $50 \mu \mathrm{L}$ of the sample. The reaction mixture was vortexed and left in the dark for 30 minutes at room temperature. The optical density was determined using a VERSA 
max microplate reader with a wavelength at $515 \mathrm{~nm}$ (Molecular Device, San Jose, CA, USA). Results were calculated using the following equation. Ac and As is the absorbance of the control and sample.

$$
\text { DPPH radical scavenging capacity }(\%)=[(\mathrm{Ac}-\mathrm{As}) / \mathrm{Ac}] \times 100
$$

\subsection{Animal Experiment}

Specific pathogen-free 6-week-old male BALB/c mice were obtained from DBL (Eumseong, Korea). The mice were acclimatized for 1 week prior to use and were housed in an air-conditioned room with a $12 \mathrm{~h}$ light/dark cycle at a temperature of $22 \pm 2{ }^{\circ} \mathrm{C}$ with $50 \pm 5 \%$ relative humidity. All experimental protocols for animal care were performed according to the rules and regulations of the Animal Ethics Committee of Jeju National University (the Institutional Animal Care and Use Committee of Jeju National University; Approval number 2018-0039) and conducted according to the Korean Animal and Plant Quarantine Agency guidelines (Laboratory Animal Guideline-75).

First, we investigated the effect of the immune system by PT extracts in mice. After acclimatization, the mice were separated for 3 groups (10 mice per group) according to body weight. The groups include Control group (no PT extracts treated), PT extracts-L (500 mg/kg PT extracts-treated group), and PT extracts-H (1000 mg/kg PT extracts-treated group) as previously described [20]. PT extracts dissolved in normal saline and mice were intragastrically administered with PT extracts once a day for 28 days. The mice spleen was collected for immunological evaluations after sacrificed by $\mathrm{CO}_{2}$ inhalation. The distribution of immune cells including B cells and T cells in splenocytes isolated from mice fed with PT extracts was evaluated by fluorescence-activated cell sorting (FACS) analysis.

Second, we investigated the effect of PT extracts on $4 \%$ dextran sulfate sodium (DSS) (MP Biomedicals Inc., Irvine, CA, USA)-induced colitis in mice. Accordingly, we divided the mice into 3 groups by body weight: Control (normal group, $n=10$ ); DSS (DSS-treated group, $n=10$ ); PTE (DSS plus PT extracts-treated group, $n=10$ ) (Figure S2A). Fecal samples were collected from each mouse at day 0 and 7 . At the end of the experiment (Day 7), the mice were sacrificed by rodent carbon dioxide $\left(\mathrm{CO}_{2}\right)$ euthanasia according to AVMA guidelines for the Euthanasia of Animals and the colon tissues were stored under $-80^{\circ} \mathrm{C}$.

\subsection{Preparation of Splenocytes and Fluorescence-Activated Cell Sorting (FACS) Analysis}

Splenocytes were obtained by gentle disruption of the spleen through sieve mesh. After the lysis of spleen tissues with $1 \times$ RBC Lysis Buffer (Roche, Basel, Switzerland), remaining cells were re-suspended in RPMI-1640 medium with 10\% fetal bovine serum, $100 \mu \mathrm{g} / \mathrm{mL}$ streptomycin and $100 \mathrm{IU} / \mathrm{mL}$ penicillin, followed by centrifugation and washing with phosphate buffered saline (WELGENE, Gyeongsan, Korea).

FACS was used to analyze sub types of the isolated splenocytes. Briefly, spleen cells were harvested and washed with 1× Dulbecco's Phosphate Buffered Saline (DPBS, WELGENE, Gyeongsan, Korea). The cells were blocked with $1 \mu \mathrm{g}$ anti-mouse IgG solution in PBS for 15 min at $4{ }^{\circ} \mathrm{C}$, and then stained with fluorescently labeled monoclonal antibodies (Biolegends, San Diego, CA, USA) for an additional $15 \mathrm{~min}$ at $4{ }^{\circ} \mathrm{C}$. Monoclonal anti-bodies were directly labeled with the following fluorescent tags; CFSE for Live/Dead cell, PE-CD3 for total T cell, APC-CD4 for helper T cell, Pacific-Blue-CD8a for cytotoxic T cell and regulatory T cell, and PE/Cy7-CD45R/B220 for B cell. After centrifugation, DPBS was added to the cells, and twenty thousand viable cells per treatment (as determined by light scatter profiles) were analyzed using a BD FACS LSR Fortessa flow cytometer (BD Biosciences, Franklin Lakes, NJ, USA).

\subsection{Disease Activity Index}

Disease activity index (DAI) scores were calculated as described in a previous study [21]. Body weight loss, stool consistency, and fecal bleeding were observed at the end of the experiment. Stool consistency was evaluated by comparing with the feces obtained from the Control. Fecal bleeding was 
observed using EZ detect colon disease test (BIOMERICA Inc., Irvine, CA, USA). The DAI score for these 3 factors were calculated as follows: weight loss ( 0 , none; 1, 1-5\%; 2, 5-10\%; 3, 10-20\%; and 4, over 20\%); stool consistency ( 0 , well form pellets; 2 , loose stool; and 4, diarrhea) and fecal bleeding ( 0 , negative; 2 , positive; and 4, gross bleeding).

\subsection{RNA Extraction and Real-Time PCR}

Total RNA was extracted from colon tissues using RNAiso Plus reagent (TaKaRa Bio. Inc., Shiga, Japan). Total RNA concentration was verified using a spectrophotometer, DS-11 plus (DENOVIX Inc., DE, USA). cDNA was synthesized from $1 \mu \mathrm{g}$ of RNA using PrimeScript ${ }^{\mathrm{TM}} 1$ st strand cDNA Synthesis Kit (Takara Bio Inc., Shiga, Japan), and oligo dT primer was used for reverse-transcription. For quantitative analysis of cytokines using real-time PCR, $1 \mu \mathrm{L}$ of cDNA was used to amplify cytokine genes, such as TNF- $\alpha$, IL-6, IL-1 $\beta$, COX-2, and $\beta$-actin using TB Green ${ }^{\text {TM }}$ Premix Ex Taq ${ }^{\text {TM }}$ (Takara Bio Inc., Shiga, Japan). The primer sequences used in this study are summarized in Table 1. PCR reactions were performed in triplicate employing Thermal Cycler Dice ${ }^{\circledR}$ Real Time System Lite (Takara Bio Inc., Shiga, Japan) using the following conditions: initial denaturation at $95^{\circ} \mathrm{C}$ for $30 \mathrm{~s}, 40$ cycles at $95^{\circ} \mathrm{C}$ for $5 \mathrm{~s}$, and $60{ }^{\circ} \mathrm{C}$ for $30 \mathrm{~s}$; dissociation curve at $95^{\circ} \mathrm{C}$ for $15 \mathrm{~s}, 60^{\circ} \mathrm{C}$ for $30 \mathrm{~s}$, and $95^{\circ} \mathrm{C}$ for $15 \mathrm{~s}$.

Table 1. Primer information for real-time PCR.

\begin{tabular}{cccc}
\hline Gene & Forward Sequences & Reverse Sequences & NCBI Number \\
\hline TNF- $\alpha$ & AGCCCCCAGTCTGTATCCTT & CATTCGAGGCTCCAGTGAAT & NM_013693.3 \\
IL-6 & AGTTGCCTTCTTGGGACTGA & CAGAATTGCCATTGCACAAC & NM_031168.2 \\
IL-1 $\beta$ & GGGCCTCAAAGGAAAGAATC & TACCAGTTGGGGAACTCTGC & NM_008361.4 \\
COX-2 & AGAAGGAAATGGCTGCAGAA & GCTCGGCTTCCAGTATTGAG & NM_011198.4 \\
$\beta$-actin & GGTGGGAATGGGTCAGAAGG & CAGCACAGGGTGCTCCTC & NM_007393.5 \\
\hline
\end{tabular}

\subsection{Histological Analysis}

The colon tissues were fixed in 10\% buffered-neutral formalin. The colon sections were subjected to alcian blue PAS staining to observe histopathological change (DKKorea, Seoul, Korea). Histological changes were examined by light microscopy. Microscopic fields for examination were chosen randomly and viewed at a magnification of $100 \times$.

\subsection{Gut Microbiota Analysis}

Fresh fecal samples were collected from each mouse at the beginning and the end of the feeding trial in this study. Total DNA from the feces was extracted using QIAamp PowerFecal DNA kit (Qiagen, Venlo, The Netherlands) according to the manufacturer's instruction. All DNA concentrations were measured using Qubit fluorometer (Invitrogen, Carlsbad, CA, USA) and adjusted to $5 \mathrm{ng} / \mu \mathrm{L}$ for MiSeq library construction using nuclease-fee sterile water. To investigate intestinal microbial community, MiSeq library construction was performed by two-step PCR according to the manufacturer's instructions. Briefly, V4 hypervariable region of the 16S rRNA gene was amplified using, and the sequencing using $5 \mu \mathrm{L}$ of forward primer (515F 5'-TCGTCGG CAGCGTCAGATGTGTATAAGAGACAGGTGCCAGCMGCCGCGGTAA-3') and reverse primer (806R 5'-GTCTCGTGGGCTCGGAGATGTGTATAAGAGACAGGGACTACHVGGGTWTCTAAT-3'), $2.5 \mu \mathrm{L}$ genomic DNA and $12.5 \mu \mathrm{L}$ 2× KAPA HiFi HotStart Ready Mix (KAPABIOSYSTEMS, Cape Town, South Africa) with the following cycle: initial denaturation at $95^{\circ} \mathrm{C}$ for $3 \mathrm{~m}, 25$ cycles at $95{ }^{\circ} \mathrm{C}$ for $30 \mathrm{~s}$, $55^{\circ} \mathrm{C}$ for $30 \mathrm{~s}$ and extension at $72{ }^{\circ} \mathrm{C}$ for $30 \mathrm{~s}$, and final extension $72{ }^{\circ} \mathrm{C}$ for $5 \mathrm{~m}$. PCR products were purified using HiAccubead (AccuGene, Incheon, Korea) according to the manufacturer's instructions. The 2nd PCR was performed in standard reaction contained $5 \mu \mathrm{L}$ PCR amplicons, $5 \mu \mathrm{L}$ index primers, $25 \mu \mathrm{L} 2 \times$ KAPA HiFi HotStart Ready Mix (KAPABIOSYSTEMS) and $10 \mu \mathrm{L}$ DNase free water with the PCR condition as follows: initial denaturation at $95^{\circ} \mathrm{C}$ for $3 \mathrm{~m}, 8$ cycles at $95{ }^{\circ} \mathrm{C}$ for $30 \mathrm{~s}, 55^{\circ} \mathrm{C}$ for $30 \mathrm{~s}$ and extension at $72{ }^{\circ} \mathrm{C}$ for $30 \mathrm{~s}$, and final extension $72{ }^{\circ} \mathrm{C}$ for $5 \mathrm{~m}$, followed by PCR purification 
with HiAccubead (AccuGene). Final PCR products from each sample were pooled in a $1.5 \mathrm{~mL}$ e-tube, and the sequencing using MiSeq was performed at Macrogen Inc. (Seoul, Korea). The output data from Miseq were analyzed using MOTHUR software [22] and the removal process of erroneous sequences was performed according to MiSeq standard operating procedure (MiSeq SOP) guidelines. In short, paired-end sequences from MiSeq were assembled using 'make.contigs' and performed the alignment process using the SILVA database (version 132) [23], singletons were removed using 'split.abund', VSEARCH was used to detect chimeric sequences [24], taxonomic classification was performed using 'classify.seqs' based on the Ribosomal Database Project (RDP) database (version 16) [25], the chimeric and non-bacterial sequences were removed using 'remove.seqs', and operational taxonomic units (OTUs) were allocated using 'opti.clust' algorithm [26]. Non-metric multidimensional scaling (NMDS) analysis was done based on Bray-Curtis dissimilarity [27]. The Phylogenetic Investigation of Communities by Reconstruction of Unobserved States 2 (PICRUSt2) was used to predict the intestinal metabolic pathways [28].

\subsection{Statistical Analysis}

The results are expressed as the means \pm standard deviation (SD). Analysis of molecular variance (AMOVA) was used to estimate significant difference of the gut microbiota in NMDS. Ellipses in NMDS were drawn with a 0.95 confidence level using $R$ vegan package. Statistical significance was accepted for $p$ values different predicted metabolic pathways and visualized for ALDEx2 effect differences $>1$ [29]. The physical parameters were compared using Student's $t$-test. In addition, the differential abundance analysis was performed using linear discriminant analysis effect size (LEfSe) analysis based on Kruskal-Wallis (KW) sum-rank test [30]. ALDEx2 [31] was used to determine significantly increased and decreased metabolic activities (effect size $>1$ ). Spearman rank correlation analysis was performed to investigate associations between LefSe-selected OTUs and ALDEx2-selected metabolic pathways. Statistical significance was accepted for $p$ values $<0.05$.

\section{Results and Discussion}

\subsection{In Vitro Antioxidant Activity of PT Extracts}

Free radicals generated by exogenous and endogenous factor play an important role in the development of diseases accompanied by inflammation of cells and animals [32]. However, antioxidants containing polyphenols and flavonoids contribute to the prevention and treatment of inflammation and disease caused by these free radicals. Furthermore, previous studies reported that PT extracts play a high radical scavenging activity due to high content of total polyphenols and total flavonoids [11,13]. These compounds strengthen the immune system and prevent some diseases such as hypertension, cancer, type 2 diabetes, and allergic disease [12,33-36]. Previous studies reported that PT extracts increased the immune system related to natural killer (NK) cell activity in clinical demonstration model [17]. Furthermore, PT extracts enhanced the secretion of cytokines in macrophages via activation of NF-kB pathway [16]. In this study, we evaluated the antioxidant capacity of PT extracts by total polyphenol content and free radical scavenging activity (Table 2). PT extracts showed high amount of total polyphenol content $(32.3 \pm 0.8 \mathrm{mg} \mathrm{GAE} / \mathrm{g})$. Furthermore, PT extracts exhibited 50\% DPPH free radical scavenging potential at $798.4 \pm 80 \mu \mathrm{g} / \mathrm{mL}$. PT extracts showed low DPPH free radical scavenging activity although total polyphenol content was high amount. Corsetto et al. [37] have previously reported that high content of total polyphenols provides anti-inflammatory activities via scavenging reactive oxygen species (ROS) or cellular endogenous defenses via enhancing antioxidant, while showing the low antioxidant capability in DPPH radical scavenging activity. Previously, we have reported that the yield rate of PT extracts was 13\% and the concentration of porphyra-334 in this PT extracts was $68.45 \pm 20 \% \mathrm{mg} / \mathrm{g}$ [17]. The main component of PT extracts, porphyra-334, has been reported to control intracellular redox condition via anti-oxidant effect through enhancing glutamate-cysteine lipase and glutamate-cysteine ligase modifier subunit levels by activating Nrf2/Keap1 pathway [38]. 
Furthermore, Ryu et al. [39] also reported that porphyra-334 enhanced the antioxidant enzymes expression by regulating Nrf2 in early response. These results indicate that the high concentration of porphyra-334 combined with polyphenol contents in PT extracts supports their potential role of reducing inflammation induced by DSS as a natural antioxidant source. Moreover, This PT extract $(500 \mathrm{mg} / \mathrm{kg})$ was reported to have increased NK cell activities and immune stimulatory effects in humans and mice, respectively $[17,20]$, suggesting that the main active compound, porphyra-334, is likely active in this concentration.

Table 2. Antioxidant capacities of PT extracts measured by total polyphenol content and DPPH radical scavenging assays.

\begin{tabular}{ccc}
\hline Extracts & $\begin{array}{c}\text { Total Polyphenol Content } \\
(\mathbf{m g} \text { GAE/g) }\end{array}$ & $\begin{array}{c}\text { DPPH Radical Scavenging } \\
\left(\mathrm{IC}_{\mathbf{5 0}} \boldsymbol{\mu} \mathbf{g} / \mathbf{m L}\right)\end{array}$ \\
\hline PT & $32.3 \pm 0.8$ & $798.4 \pm 80$ \\
\hline \multicolumn{2}{c}{ Results represented as mean values from three repetition $\pm \mathrm{SD}}$.
\end{tabular}

\subsection{Effects of Differentiation of $T$ and B Cells by PT Extracts}

Before the DSS treatment, we investigated the effects of low $(500 \mathrm{mg}$ of PT extracts $/ \mathrm{kg}$ of body weight; PT extracts-L) and high (1000 mg of PT extracts/kg of body weight; PT extracts-H) concentration of PT extracts on mice immune system. PT extracts dissolved in normal saline and mice were intragastrically administered to mice. Flow cytometry was used to analyze the distribution of $\mathrm{CD} 45 \mathrm{R} / \mathrm{B} 220^{+} \mathrm{B}$ cells and $\mathrm{CD}^{+} \mathrm{T}$ cells in splenocytes (Figure 1).

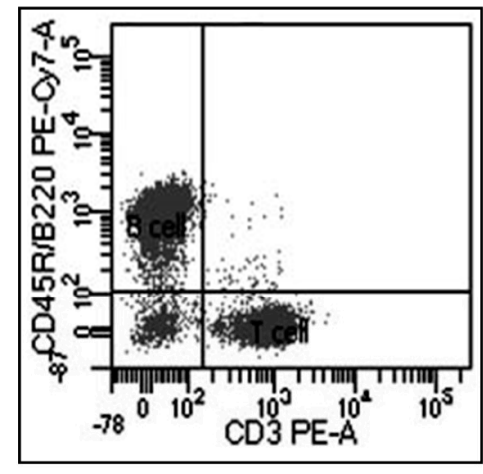

PT extracts-L

PT extracts-H
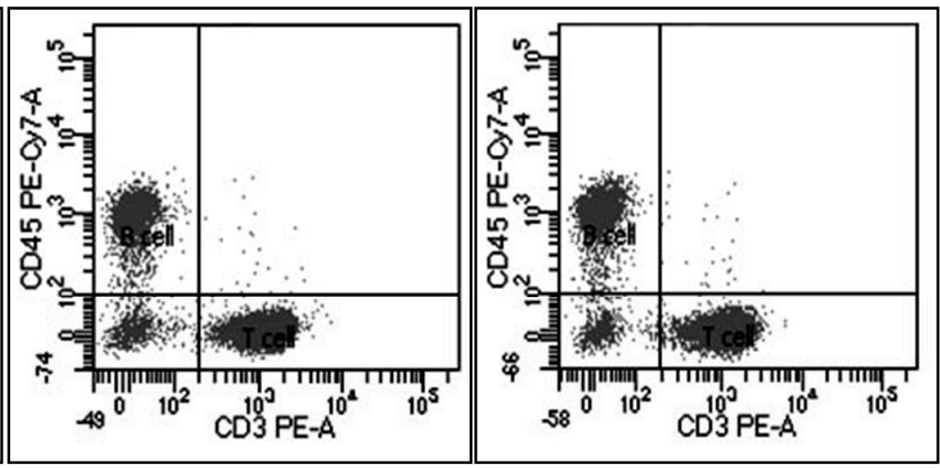

$+$

$+$

Figure 1. Effect of PT extracts on T cell population change. Flow cytometry analysis was performed to evaluate the effect of PT extracts on the populations of CD45R/B220 $0^{+}$B cells and $\mathrm{CD}^{+} \mathrm{T}$ cells.

Table 3 showed that both high and low concentrations of PT extracts increased T cells approximately $20 \%$ without changing the ratio of Tc cell and Th/Treg cell. It has been reported that depletions of $\mathrm{T}$ cell and Treg cell were associated with severe mucosal injury [40-43], suggesting that the increased amount of $\mathrm{T}$ cells may play a role in alleviating damages caused by DSS-induced colitis. These results suggest that PT extracts changed the balance of the immune system by increasing the $\mathrm{T}$ cell population in mice, but it did not show a concentration-dependent pattern. Previously, Kang et al. [20] reported PT extracts showed no cytotoxicity in mice, while LDH assay showed dose-dependent cytotoxicity in PT extracts. As our results showed no significant difference between the concentrations of PT extracts (Table 3), we applied lower concentration of PT extracts for DSS-induced colitis experiments. 
Table 3. The distribution of immune cells, including B cells and T cells, in splenocytes isolated from normal diet-fed mice.

\begin{tabular}{|c|c|c|c|c|}
\hline \multirow{2}{*}{ Group } & \multirow{2}{*}{ Live Cell } & \multirow{2}{*}{ B Cell (CD45R/B220) } & \multicolumn{2}{|c|}{ T Cell (CD3) } \\
\hline & & & Tc Cell (CD8) & Th/Treg Cell (CD4) \\
\hline \multirow{2}{*}{$\begin{array}{c}\text { Control } \\
n=10\end{array}$} & \multirow{2}{*}{$10,377 \pm 55$} & \multirow{2}{*}{$\begin{array}{c}5056 \pm 179 \\
(48.74 \%)\end{array}$} & \multicolumn{2}{|c|}{$\begin{array}{c}4595 \pm 172 \\
(44.27 \%)\end{array}$} \\
\hline & & & $\begin{array}{l}1344 \pm 52 \\
(29.43 \%)\end{array}$ & $\begin{array}{c}3151 \pm 154 \\
(68.41 \%)\end{array}$ \\
\hline \multirow{2}{*}{$\begin{array}{l}\text { PT extracts-L } \\
\quad n=10\end{array}$} & \multirow{2}{*}{$9687 \pm 16$} & \multirow{2}{*}{$\begin{array}{c}2528 \pm 91 \\
(26.10 \%)\end{array}$} & \multicolumn{2}{|c|}{$\begin{array}{c}6424 \pm 106^{*} \\
(66.31 \%)\end{array}$} \\
\hline & & & $\begin{array}{c}1804 \pm 47^{*} \\
(28.16 \%)\end{array}$ & $\begin{array}{c}4499 \pm 134^{*} \\
(69.93 \%)\end{array}$ \\
\hline \multirow{2}{*}{$\begin{array}{l}\text { PT extracts-H } \\
\quad n=10\end{array}$} & \multirow{2}{*}{$9635 \pm 32$} & \multirow{2}{*}{$\begin{array}{c}2788 \pm 105 \\
(28.93 \%)\end{array}$} & \multicolumn{2}{|c|}{$\begin{array}{c}6240 \pm 156 * \\
(64.75 \%)\end{array}$} \\
\hline & & & $\begin{array}{c}1707 \pm 44 * \\
(27.44 \%)\end{array}$ & $\begin{array}{c}4435 \pm 158 * \\
(70.97 \%)\end{array}$ \\
\hline
\end{tabular}

Results are represented as the mean \pm SD. ${ }^{*} p<0.05$ represent significant increase compared to control. Control, Normal group; PT, Porphyra tenera; PT extracts-L, Low concentration of PT extracts (500 mg/kg)-treated group; PT extracts-H, High concentration of PT extracts $(1000 \mathrm{mg} / \mathrm{kg})$-treated group.

\subsection{Inhibitory Effects of PT Extracts on DSS-Reduced Colitis Symptoms}

Previous studies have shown that clinical symptoms of ulcerative colitis caused by DSS were body weight loss, colon length loss, and diarrhea [44]. In this study, we investigated the inhibitory effect of PT extracts on DSS-induced colitis symptoms in mice. While administration of DSS to mice significantly decreased their body weight, which was significantly ameliorated by feeding PT extracts (Table 4). DSS treatment also significantly shortened the length of the colon in DSS group compared to Control group ( $p<0.05)$, which was slightly recovered by the PT extracts treatment (Figure 2A). In addition, increased DAI score by DSS treatment was significantly attenuated by PT extracts, suggesting that the clinical colitis symptom severity was effectively alleviated by PT extracts (Figure 2B). Moreover, DSS group exhibited severe colitis symptoms evidenced by the disappearance of goblet cells, superficial epithelial cells, and the increase of inflammatory cell infiltration in lamina propria and submucosa. PTE group showed that the histological damage was slightly alleviated (Figure S2B).

Table 4. Effects of PT extracts on the body weight loss by DSS.

\begin{tabular}{cccc}
\hline Group & D0 & D7 & Body Weight Loss \\
\hline Control $(n=10)$ & $21.6 \pm 0.51$ & $20.9 \pm 0.32$ & $0.8 \pm 0.57$ \\
DSS $(n=10)$ & $21.4 \pm 0.73$ & $19.0 \pm 0.58$ & $2.3 \pm 0.15^{\#}$ \\
PTE $(n=10)$ & $21.6 \pm 0.61$ & $20.3 \pm 0.66$ & $0.9 \pm 0.34 *$
\end{tabular}

Control, Normal group; DSS, Dextran sulfate sodium-treated group; PTE, PT extracts ( $500 \mathrm{mg} / \mathrm{kg}$ )-treated group. Compared with Control group, ${ }^{\#} p<0.05$, Compared with DSS group, ${ }^{*} p<0.05$. 


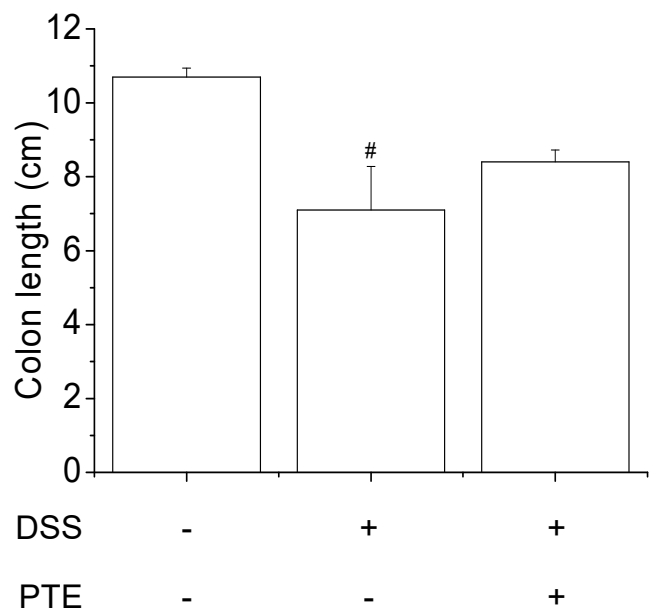

B

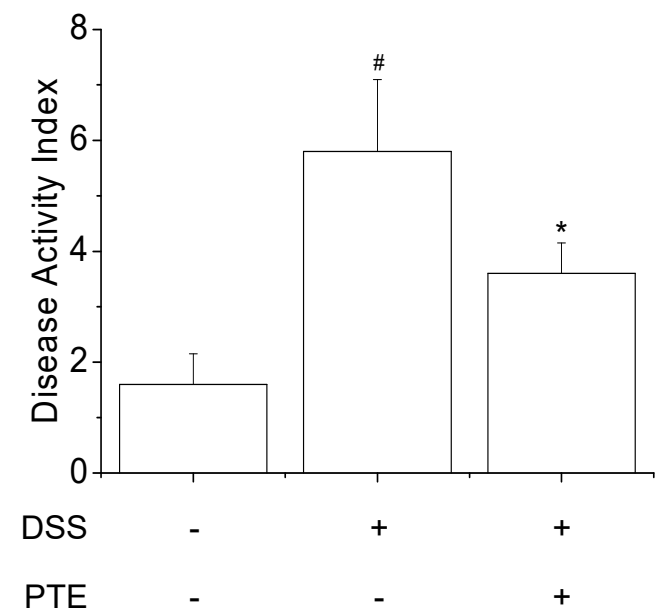

Figure 2. Effects of PT extracts on colitis development in DSS-treated mice. (A) Colon length in each group of the PT extracts treatments. Colon length was measured by ruler at the end of the experiment. (B) The disease activity index (DAI) score. The DAI is the sum of the three parameters such as body weight loss, stool consistency, and stool bleeding. All results are expressed as the means $\pm \operatorname{SD}(n=10)$. Compared with Control group, ${ }^{\#} p<0.05$, Compared with DSS-treated group, ${ }^{*} p<0.05$. Control, DSS, and PTE indicated normal group, DSS-treated group, and DSS plus PT extracts-fed group, respectively.

\subsection{Inhibitory Effects of PT Extracts on DSS-Induced Inflammatory Markers}

Previously, the PT extracts used in this study were reported to enhance immune stimulatory effects through production of nitric oxide (NO) and expression of proinflammatory markers (IL-1 $\beta$, IL-2, IL-4, IFN- $\gamma$, and iNOS) [20]. DSS is known to induce inflammation in the colon and play an important role in controlling the morphology of epithelial and goblet cells [45]. The inflammatory cytokine is known to reflect the degree of colonic inflammation by inducing inflammatory responses by DSS [46]. Previously, it has been reported that a toxicity of DSS increases the production of macrophage-derived cytokine such as IL-1 $\beta$, IL-6 and TNF- $\alpha$, and disrupts colonic epithelial cells [47]. To study the anti-inflammatory effect of PT extracts on DSS-treated mice, the mRNA expression of inflammatory markers in colon were determined. As shown in Figure 3, the mRNA expression of inflammatory markers (TNF- $\alpha$, IL-6, IL-1 $\beta$ and COX-2) in mice colon was significantly increased after the treatment of DSS. However, the mRNA expression level of these inflammatory markers in the colon was significantly inhibited in colitis-induced mice administrated with PT extracts. It was reported that the extract from P. yezonesis reduced nitric oxide and reactive oxygen species as well as mRNA expression levels of inflammatory cytokines by controlling Toll-like receptor 4 (TLR4), which suppressed the activation of NF- $\kappa B$ and MAP kinases [48]. Recently, it has been reported that an increase of IL-6 leads to an inhibition response of Treg cell production, promoting the differentiation of $\mathrm{T}_{0}$ cell into Th17 cell [49,50]. Therefore, our results suggest that PT extracts treatment have shown anti-inflammatory activity on DSS-induced colitis mice via inhibiting inflammatory markers such as IL-6, leading to increase in T cell population. 
A

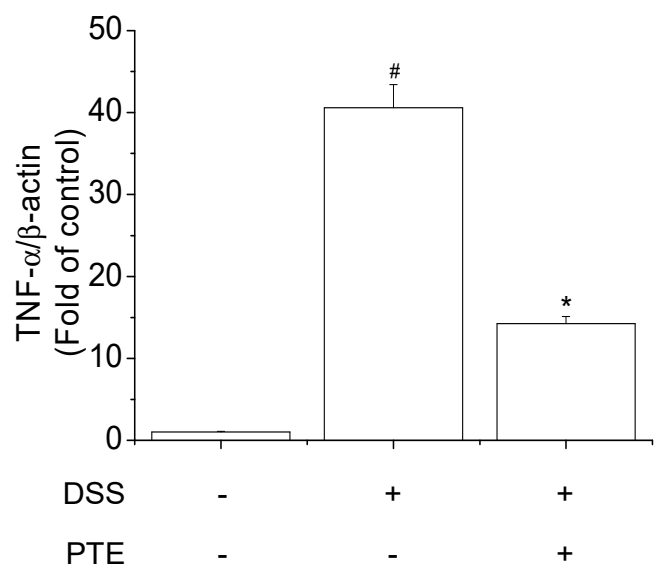

C

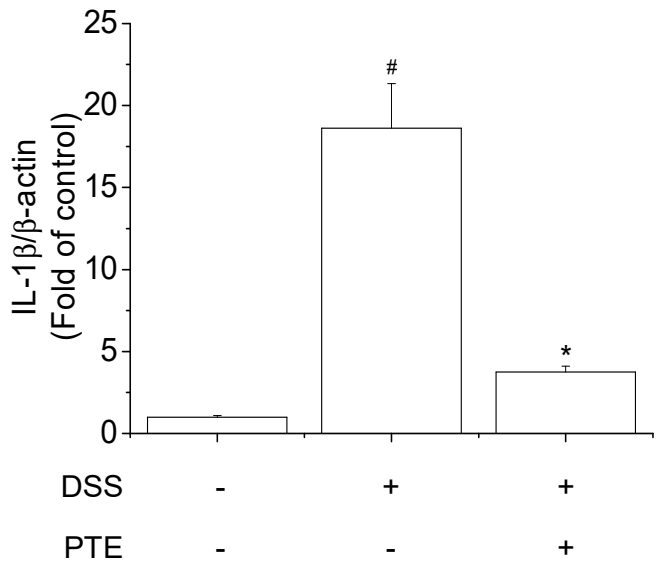

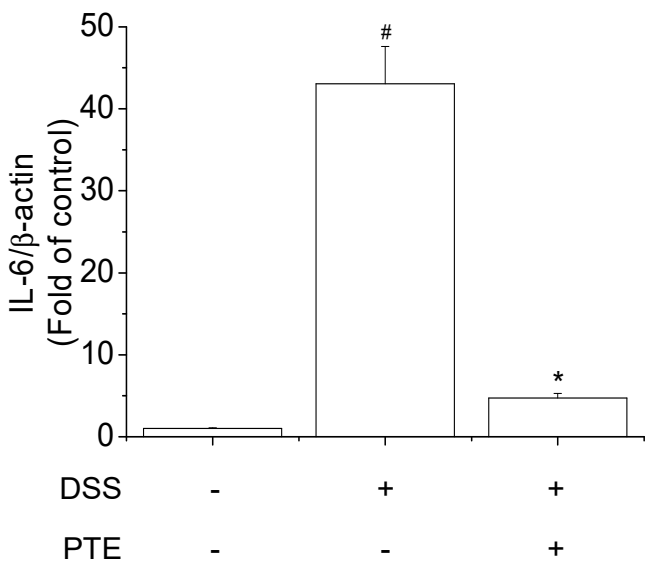

D

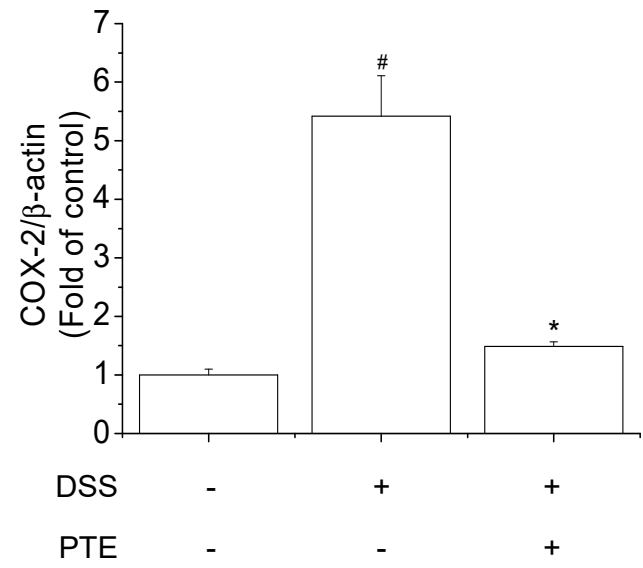

Figure 3. Effects of PT extracts on inflammatory markers in colon of DSS-treated mice. The mRNA expression of inflammatory markers was determined by real-time PCR primer of (A) TNF- $\alpha$, (B) IL-6, (C) IL-1 $\beta$, and (D) COX-2 in colon of DSS-treated mice. All results are expressed as the means \pm SD $(\mathrm{n}=10)$. Compared with Control group, ${ }^{\#} p<0.05$, Compared with DSS group, ${ }^{*} p<0.05$. Control, DSS, and PTE indicated normal group, DSS-treated group, and DSS plus PT extracts-fed group, respectively.

\subsection{Alteration of Gut Microbiota by PT Extracts on Colitis-Induced Mice}

In non-multidimensional scaling (NMDS) analysis, the gut microbiota of CTL group was significantly different from DSS-treated groups $(p<0.001)$ (Figure 4A), indicating dysbiosis induced by DSS treatment. In addition, although the gut microbiota of DSS and PTE groups were close to each other in NMDS analysis, the results from AMOVA suggested that both DSS and PT extracts treatments significantly shifted the gut microbiota $(p=0.001)$. DSS treatment significantly decreased the abundance of the phylum Firmicutes $(p<0.001)$ and increased the genus Bacteroides $(p<0.01)$ (Figure 4B). There were 7,2 , and 2 genera whose abundance were significantly changed by DSS treatments, PT extracts, and both, respectively. Genera decreased by DSS include butyrate producing bacteria (i.e., Alistipes, Oscillibacter, Acetatifactor, and Clostridium_XIVb), while DSS increased the abundance of some of the potentially pathogenic bacteria (i.e., Helicobacter, Mucispirillum, and Parasutterella). On the other hand, PT extracts increased the abundance of Clostridium_XIVb, while decreasing the abundance of beneficial bacteria (i.e., Alistipes and Lactobacillus). Members of Clostridium_XIVb include cellulolytic bacteria and lactose-fermenting butyrate-producers [51]. Our results suggest that the increase in the abundance of 
Clostridium_XIVb may have affected the abundance of other polysaccharide utilizing bacteria such as Alistipes and Lactobacillus.

We also analyzed the effects of PT extracts on the intestinal metabolic pathways which were predicted based on gut microbial communities (Figure 4C). Among the predicted metabolic pathways, PT extracts depleted 'lactose and galactose degradation', allowing more bioavailability of lactose and galactose in gut. On the other hand, PT extracts enriched eight metabolic pathways in colitis-induced mice. Enriched glyoxylate cycle and ethylmalonyl-coA pathway may suggest that increased amount of succinate which can be used to produce short chain fatty acids, especially butyrate, in gut. Enriched nitrate reduction may suggest that increased nitrate bioavailability in gut. Hu et al. [52] reported that oral administration of nitrate regulated gut homeostasis and ameliorated DSS-induced colitis. Moreover, increased creatinine degradation indicates improved creatinine clearance and lower inflammation in renal fibrosis [53]. PT extracts enriched glycine betaine metabolism. It has been reported that administration of betaine inhibited inflammatory markers such TNF- $\alpha$, IL-6, iNOS [54]. While results in Figure $4 \mathrm{C}$ suggest that PT extracts enhanced beneficial metabolic pathways in ameliorating DSS-induced colitis, PT extracts supplemented to non-DSS treated mice showed none of these beneficial effects (Figure S3). These results suggest that PT extracts may have ameliorated the damages caused by DSS-treatment through shifting DSS-induced gut dysbiosis. Together, our results suggest that PT extracts enriched beneficial metabolic pathways that may ameliorate adverse effects caused by DSS treatment. Intestinal bacteria produce butyrate through four pathways, namely acetyl-CoA, glutarate, 4-aminobutyrate/succinate and lysine pathways [55]. Among them, PT extracts enriched KEGG orthologues related to acetyl-CoA and 4-aminobytyrate pathways (Figure S4 and Table S1). It has been reported that Production of luminal butyrate by gut microbiota induce the differentiation of colonic regulatory T cells [56]. Therefore, our results indicate that PT extracts improve host's immune system through shifting gut microbiota and their metabolic roles in gut.

In this study, we evaluated the effect of anti-inflammatory properties and gut microbiota modulation of Porphyra tenera (PT) extracts in DSS-induced colitis model. Previously, we reported PT extracts contain bioactive compound porphyra334 [20], approximately $16 \%$ of the total. Our results showed $500 \mathrm{mg} / \mathrm{kg}$ of PT extracts improved immune in DSS-treated mice, suggesting that $80 \mathrm{mg} / \mathrm{kg}$ of porphyra334 could bring the same beneficial effects. Further study should investigate the effects of porphyra334 for the development of functional food and supplements. The current study found that the PT extracts has beneficial effects on DSS-induced colitis disorders such as improving the body weight loss, colon length loss, and disease activity index (DAI) score of the colitis-induced mice. Moreover, PT extracts significantly restored the DSS-induced inflammation through enhancing the antioxidant activities in colitis mice. Importantly, we found that the PT extracts reshaped the gut microbes in DSS-treated mice. In this study, we did not evaluate oxidative stress nor expression of antioxidant enzymes. However, as increasing evidence suggested that DSS creates oxidative stress in mice [57] and induces pro-inflammatory cytokines [58]; thus, antioxidants are suggested to be used to treat IBD [59]. Moreover, a number of studies have reported that antioxidants alter cytokine production [60-62]. Our results showed antioxidant potential in PT extracts as well as reduction of pro-inflammatory cytokines by PT extracts. Therefore, it is likely that antioxidant activities of PT extracts ameliorated DSS-induced damages in mice. 

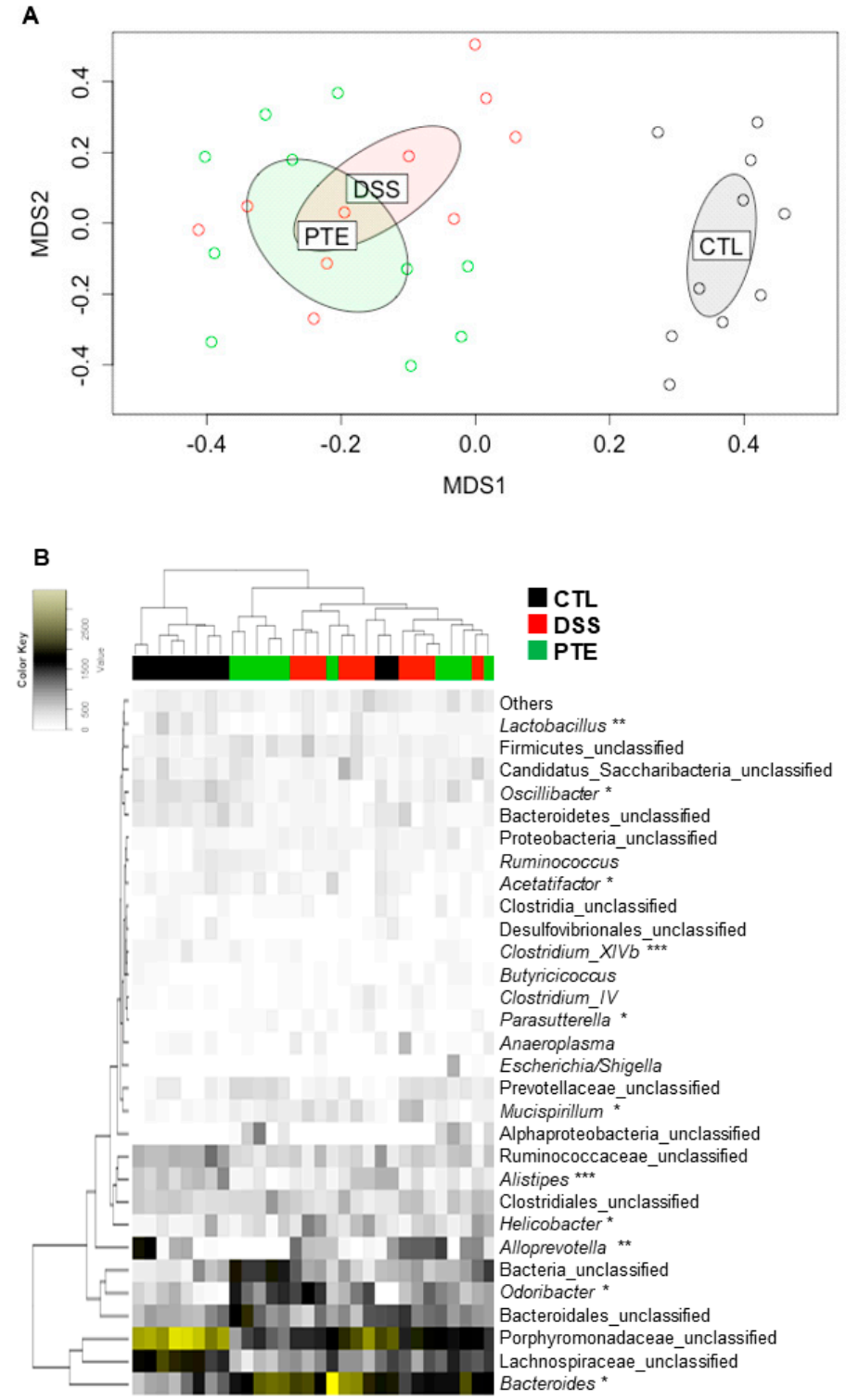

C

DSS VS PTE

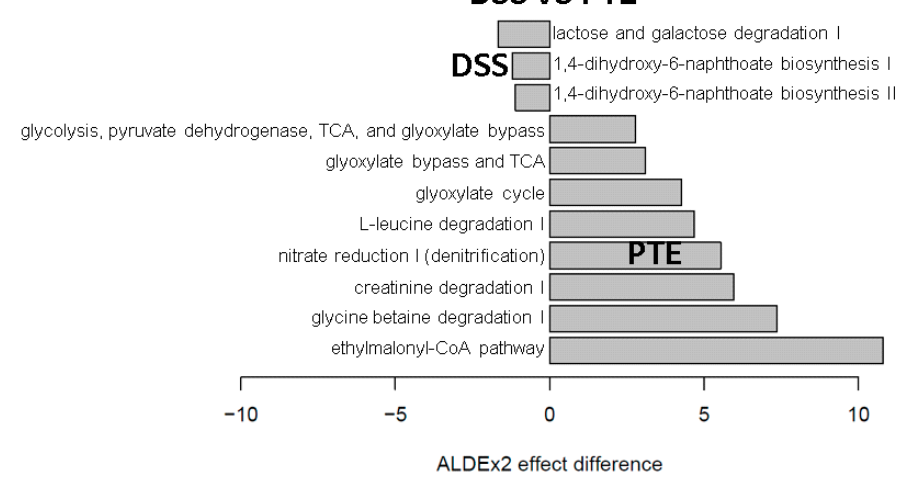

Figure 4. The comparison analysis of microbial community $(n=10)$ using non-metric multidimensional scaling (NMDS) plotting and heatmap. (A) NMDS analysis. The ellipses were drawn with 0.95 confidence level in NMDS plotting. (B) Genus level taxonomic composition of relative abundance in the mice gut microbiota. ${ }^{*}{ }^{* *}$, and ${ }^{* * *}$ indicate significant difference between CTL and DSS, DSS and PTE, and both, respectively. (C) Differentially abundant predicted metabolic pathways in DSS and PTE groups. CTL, DSS, and PTE indicate normal group, DSS-treated group and DSS plus PT extracts-treated group, respectively. 


\section{Conclusions}

Here, we conclude that PT extracts have potential antioxidants and anti-inflammatory properties as well as capabilities of modulating gut microbiota, which ameliorates DSS-induced colitis. Further studies, however, are required to confirm these in clinical trials.

Supplementary Materials: The following are available online at http://www.mdpi.com/2076-3921/9/10/988/s1, Figure S1: The sampling location of Porphyra tenera (Soan-do; $38^{\circ} 8^{\prime} 29.36^{\prime \prime}$ N, $126^{\circ} 39^{\prime} 22.59^{\prime \prime}$ E), Figure S2: Experiment design of animal experiment (A) and representative images of histological changes, Figure S3. Non-multidimensional scaling analysis showing gut microbiota difference at Day 0 (A) and Day 7 (B). Ellipses in NMDS were drawn with a 0.95 confidence level using $R$ vegan package. Differentially abundant predicted metabolic pathways in CTL and NPTE groups (C). NPTE, PTE, DSS, and CTL indicate mice treated with PT extracts, mice treated with PT extracts and DSS, mice treated with DSS, and control mice not treated with PT extracts nor DSS, respectively. Figure S4: Significantly enriched and depleted KEGG orthologues (KO) in the butanoate metabolism, Table S1: The detail description of significantly enriched and depleted butanoate metabolic pathways.

Author Contributions: Conceptualization, J.K. and T.U.; methodology, J.K., T.O., B.A., and T.U.; software, J.K. and T.U.; validation, J.H.C.; formal analysis, J.K., J.H.C., and T.U.; investigation, J.K., G.K. and H.J.; resources, J.K. and T.U.; data curation, J.H.C. and T.U.; writing-original draft preparation, J.K. and J.H.C.; writing-review and editing, J.H.C. and T.U.; visualization, J.K., J.H.C., and T.U.; supervision, T.U.; project administration, T.U.; funding acquisition, T.O., B.A. and T.U. All authors have read and agreed to the published version of the manuscript.

Funding: This research was supported, in part, by the Basic Science Research Program through the National Research Foundation of Korea (NRF) funded by the Ministry of Education (2016R1A6A1A03012862) and the project titled 'Industrialization of food materials for health promotion derived from algae in the jeonnam region', funded by Marine Biotechnology Program Funded by Ministry of Oceans and Fisheries, Republic of Korea.

Acknowledgments: We are grateful to Sustainable Agriculture Research Institute (SARI) in Jeju National University for providing the experimental facilities.

Conflicts of Interest: The authors declare no conflict of interest.

\section{References}

1. Sittipo, P.; Shim, J.W.; Lee, Y.K. Microbial metabolites determine host health and the status of some diseases. Int. J. Mol. Sci. 2019, 20, 5296. [CrossRef] [PubMed]

2. Yin, X.; Lee, B.; Zaragoza, J.; Marco, M.L. Dietary perturbations alter the ecological significance of ingested Lactobacillus plantarum in the digestive tract. Sci. Rep. 2017, 7, 7267. [CrossRef] [PubMed]

3. Bailey, M.J.; Naik, N.N.; Wild, L.E.; Patterson, W.B.; Alderete, T.L. Exposure to air pollutants and the gut microbiota: A potential link between exposure, obesity, and type 2 diabetes. Gut Microbes 2020, 11, 1188-1202. [CrossRef] [PubMed]

4. Lee, N.Y.; Yoon, S.J.; Han, D.H.; Gupta, H.; Youn, G.S.; Shin, M.J.; Ham, Y.L.; Kwak, M.J.; Kim, B.Y.; Yu, J.S.; et al. Lactobacillus and Pediococcus ameliorate progression of non-alcoholic fatty liver disease through modulation of the gut microbiome. Gut Microbes 2020, 11, 882-899. [CrossRef]

5. Zhao, Y.; Wang, Z. Gut microbiome and cardiovascular disease. Curr. Opin. Cardiol. 2020, 35, $207-218$. [CrossRef]

6. Nair, A.T.; Ramachandran, V.; Joghee, N.M.; Antony, S.; Ramalingam, G. Gut microbiota dysfunction as reliable non-invasive early diagnostic biomarkers in the pathophysiology of Parkinson's disease: A critical review. J. Neurogastroenterol. Motil. 2018, 24, 30-42. [CrossRef] [PubMed]

7. Verdugo-Meza, A.; Ye, J.; Dadlani, H.; Ghosh, S.; Gibson, D.L. Connecting the dots between inflammatory bowel disease and metabolic syndrome: A focus on gut-derived metabolites. Nutrients 2020, 12, 1434. [CrossRef]

8. Shamoon, M.; Martin, N.M.; O'Brien, C.L. Recent advances in gut microbiota mediated therapeutic targets in inflammatory bowel diseases: Emerging modalities for future pharmacological implications. Pharmacol. Res. 2019, 148, 104344. [CrossRef]

9. Leonard, S.G.; Sweeney, T.; Bahar, B.; Lynch, B.P.; O’Doherty, J.V. Effect of dietary seaweed extracts and fish oil supplementation in sows on performance, intestinal microflora, intestinal morphology, volatile fatty acid concentrations and immune status of weaned pigs. Br. J. Nutr. 2011, 105, 549-560. [CrossRef] 
10. Zhang, Z.S.; Wang, X.M.; Han, Z.P.; Yin, L.; Zhao, M.X.; Yu, S.C. Physicochemical properties and inhibition effect on iron deficiency anemia of a novel polysaccharide-iron complex (LPPC). Bioorg. Med. Chem. Lett. 2012, 22, 489-492. [CrossRef]

11. Hwang, E.S.; Thi, N.D. Effects of extraction and processing methods on antioxidant compound contents and radical scavenging activities of laver (Porphyra tenera). Prev. Nutr. Food Sci. 2014, 19, 40-48. [CrossRef] [PubMed]

12. Ishihara, K.; Oyamada, C.; Matsushima, R.; Murata, M.; Muraoka, T. Inhibitory effect of porphyran, prepared from dried "Nori", on contact hypersensitivity in mice. Biosci. Biotechnol. Biochem. 2005, 69, 1824-1830. [CrossRef] [PubMed]

13. Patra, J.K.; Lee, S.W.; Kwon, Y.S.; Park, J.G.; Baek, K.H. Chemical characterization and antioxidant potential of volatile oil from an edible seaweed Porphyra tenera (Kjellman, 1897). Chem. Cent. J. 2017, 11, 34. [CrossRef] [PubMed]

14. Rui, Y.; Zhaohui, Z.; Wenshan, S.; Bafang, L.; Hu, H. Protective effect of MAAs extracted from Porphyra tenera against UV irradiation-induced photoaging in mouse skin. J. Photochem. Photobiol. B 2019, 192, $26-33$. [CrossRef]

15. Ichihara, T.; Wanibuchi, H.; Taniyama, T.; Okai, Y.; Yano, Y.; Otani, S.; Imaoka, S.; Funae, Y.; Fukushima, S. Inhibition of liver glutathione S-transferase placental form-positive foci development in the rat hepatocarcinogenesis by Porphyra tenera (Asakusa-nori). Cancer Lett. 1999, 141, 211-218. [CrossRef]

16. Song, J.H.; Kang, H.B.; Park, S.H.; Jeong, J.H.; Park, J.; You, Y.; Lee, Y.H.; Lee, J.; Kim, E.; Choi, K.C.; et al. Extracts of Porphyra tenera (Nori seaweed) activate the immune response in mouse RAW264.7 macrophages via NF-kappaB signaling. J. Med. Food 2017, 20, 1152-1159. [CrossRef]

17. Jung, S.J.; Jang, H.Y.; Jung, E.S.; Noh, S.O.; Shin, S.W.; Ha, K.C.; Baek, H.I.; Ahn, B.J.; Oh, T.H.; Chae, S.W. Effects of Porphyra tenera supplementation on the immune system: A randomized, double-blind, and placebo-controlled clinical trial. Nutrients 2020, 12, 1642. [CrossRef]

18. Re, R.; Pellegrini, N.; Proteggente, A.; Pannala, A.; Yang, M.; Rice-Evans, C. Antioxidant activity applying an improved ABTS radical cation decolorization assay. Free Radic. Biol. Med. 1999, 26, 1231-1237. [CrossRef]

19. Dudonne, S.; Vitrac, X.; Coutiere, P.; Woillez, M.; Merillon, J.M. Comparative study of antioxidant properties and total phenolic content of 30 plant extracts of industrial interest using DPPH, ABTS, FRAP, SOD, and ORAC assays. J. Agric. Food Chem. 2009, 57, 1768-1774. [CrossRef]

20. Kang, H.-B.; Song, J.; You, Y.; Park, J.; Kwak, S.; Lee, Y.; Lee, J.; Kim, S.-I.; Choi, K.; Jun, W. Porphyra tenera extracts have immune stimulation activity via increasing cytokines in mouse primary splenocytes and RAW264.7 macrophages. J. Food Nutr. Res. 2016, 4, 558-565.

21. Best, W.R.; Becktel, J.M.; Singleton, J.W.; Kern, F., Jr. Development of a Crohn's disease activity index. National cooperative Crohn's disease study. Gastroenterology 1976, 70, 439-444. [CrossRef]

22. Schloss, P.D.; Westcott, S.L.; Ryabin, T.; Hall, J.R.; Hartmann, M.; Hollister, E.B.; Lesniewski, R.A.; Oakley, B.B.; Parks, D.H.; Robinson, C.J.; et al. Introducing mothur: Open-source, platform-independent, community-supported software for describing and comparing microbial communities. Appl. Environ. Microbiol. 2009, 75, 7537-7541. [CrossRef] [PubMed]

23. Quast, C.; Pruesse, E.; Yilmaz, P.; Gerken, J.; Schweer, T.; Yarza, P.; Peplies, J.; Glockner, F.O. The SILVA ribosomal RNA gene database project: Improved data processing and web-based tools. Nucleic Acids Res. 2013, 41, D590-D596. [CrossRef] [PubMed]

24. Rognes, T.; Flouri, T.; Nichols, B.; Quince, C.; Mahe, F. VSEARCH: A versatile open source tool for metagenomics. Peer] 2016, 4, e2584. [CrossRef] [PubMed]

25. Cole, J.R.; Chai, B.; Farris, R.J.; Wang, Q.; Kulam, S.A.; McGarrell, D.M.; Garrity, G.M.; Tiedje, J.M. The ribosomal database project (RDP-II): Sequences and tools for high-throughput rRNA analysis. Nucleic Acids Res. 2005, 33, D294-D296. [CrossRef] [PubMed]

26. Westcott, S.L.; Schloss, P.D. OptiClust, an improved method for assigning amplicon-based sequence data to operational taxonomic units. MSphere 2017, 2, e00073-17. [CrossRef] [PubMed]

27. Beals, E.W. Bray-Curtis ordination-An effective strategy for analysis of multivariate ecological data. Adv. Ecol. Res. 1984, 14, 1-55. [CrossRef]

28. Douglas, G.M.; Maffei, V.J.; Zaneveld, J.R.; Yurgel, S.N.; Brown, J.R.; Taylor, C.M.; Huttenhower, C.; Langille, M.G.I. PICRUSt2 for prediction of metagenome functions. Nat. Biotechnol. 2020, 38, 685-688. [CrossRef] 
29. Fernandes, A.D.; Reid, J.N.; Macklaim, J.M.; McMurrough, T.A.; Edgell, D.R.; Gloor, G.B. Unifying the analysis of high-throughput sequencing datasets: Characterizing RNA-seq, $16 \mathrm{~S}$ rRNA gene sequencing and selective growth experiments by compositional data analysis. Microbiome 2014, 2, 15. [CrossRef]

30. Segata, N.; Izard, J.; Waldron, L.; Gevers, D.; Miropolsky, L.; Garrett, W.S.; Huttenhower, C. Metagenomic biomarker discovery and explanation. Genome Biol. 2011, 12, R60. [CrossRef]

31. Fernandes, A.D.; Macklaim, J.M.; Linn, T.G.; Reid, G.; Gloor, G.B. ANOVA-like differential expression (ALDEx) analysis for mixed population RNA-Seq. PLoS ONE 2013, 8, e67019. [CrossRef] [PubMed]

32. Sivandzade, F.; Prasad, S.; Bhalerao, A.; Cucullo, L. Nrf2 and NF-kappaB interplay in cerebrovascular and neurodegenerative disorders: Molecular mechanisms and possible therapeutic approaches. Redox Biol. 2019, 21, 101059. [CrossRef] [PubMed]

33. Cian, R.E.; Alaiz, M.; Vioque, J.; Drago, S.R. Enzyme proteolysis enhanced extraction of ACE inhibitory and antioxidant compounds (peptides and polyphenols) from Porphyra columbina residual cake. J. Appl. Phycol. 2013, 25, 1197-1206. [CrossRef]

34. Yu, X.J.; Zhou, C.S.; Yang, H.; Huang, X.Y.; Ma, H.L.; Qin, X.P.; Hu, J.L. Effect of ultrasonic treatment on the degradation and inhibition cancer cell lines of polysaccharides from Porphyra yezoensis. Carbohyd. Polym. 2015, 117, 650-656. [CrossRef]

35. Venkatraman, K.L.; Mehta, A. Health benefits and pharmacological rffects of Porphyra species. Plant. Foods Hum. Nutr. 2019, 74, 10-17. [CrossRef]

36. Murray, M.; Dordevic, A.L.; Ryan, L.; Bonham, M.P. The impact of a single dose of a polyphenol-rich seaweed extract on postprandial glycaemic control in healthy adults: A randomised cross-over trial. Nutrients 2018, 10, 270. [CrossRef]

37. Corsetto, P.A.; Montorfano, G.; Zava, S.; Colombo, I.; Ingadottir, B.; Jonsdottir, R.; Sveinsdottir, K.; Rizzo, A.M. Characterization of antioxidant potential of seaweed extracts for enrichment of convenience food. Antioxidants 2020, 9, 249. [CrossRef]

38. Gacesa, R.; Lawrence, K.P.; Georgakopoulos, N.D.; Yabe, K.; Dunlap, W.C.; Barlow, D.J.; Wells, G.; Young, A.R.; Long, P.F. The mycosporine-like amino acids porphyra-334 and shinorine are antioxidants and direct antagonists of Keap1-Nrf2 binding. Biochimie 2018, 154, 35-44. [CrossRef]

39. Ryu, J.; Kwon, M.J.; Nam, T.J. Nrf2 and NF-kappaB signaling pathways contribute to porphyra-334-mediated inhibition of UVA-induced inflammation in skin fibroblasts. Mar. Drugs 2015, 13, 4721-4732. [CrossRef]

40. Chen, Y.; Chou, K.; Fuchs, E.; Havran, W.L.; Boismenu, R. Protection of the intestinal mucosa by intraepithelial gamma delta T cells. Proc. Natl. Acad. Sci. USA 2002, 99, 14338-14343. [CrossRef]

41. Iliev, I.D.; Mileti, E.; Matteoli, G.; Chieppa, M.; Rescigno, M. Intestinal epithelial cells promote colitis-protective regulatory T-cell differentiation through dendritic cell conditioning. Mucosal Immunol. 2009, 2, 340-350. [CrossRef] [PubMed]

42. Annacker, O.; Coombes, J.L.; Malmstrom, V.; Uhlig, H.H.; Bourne, T.; Johansson-Lindbom, B.; Agace, W.W.; Parker, C.M.; Powrie, F. Essential role for CD103 in the T cell-mediated regulation of experimental colitis. J. Exp. Med. 2005, 202, 1051-1061. [CrossRef] [PubMed]

43. Nyborg, A.C.; Zacco, A.; Ettinger, R.; Jack Borrok, M.; Zhu, J.; Martin, T.; Woods, R.; Kiefer, C.; Bowen, M.A.; Suzanne Cohen, E.; et al. Development of an antibody that neutralizes soluble IgE and eliminates $\operatorname{IgE}$ expressing B cells. Cell. Mol. Immunol. 2016, 13, 391-400. [CrossRef]

44. Zhu, Y.; Li, X.; Chen, J.; Chen, T.; Shi, Z.; Lei, M.; Zhang, Y.; Bai, P.; Li, Y.; Fei, X. The pentacyclic triterpene Lupeol switches M1 macrophages to M2 and ameliorates experimental inflammatory bowel disease. Int. Immunopharmacol. 2016, 30, 74-84. [CrossRef] [PubMed]

45. Hu, L.; Wu, C.; Zhang, Z.; Liu, M.; Maruthi Prasad, E.; Chen, Y.; Wang, K. Pinocembrin protects against dextran sulfate sodium-Induced rats colitis by ameliorating inflammation, improving barrier function and modulating gut microbiota. Front. Physiol. 2019, 10, 908. [CrossRef] [PubMed]

46. Siddiqi, M.; Nusrat, S.; Alam, P.; Malik, S.; Chaturvedi, S.K.; Ajmal, M.R.; Abdelhameed, A.S.; Khan, R.H. Investigating the site selective binding of busulfan to human serum albumin: Biophysical and molecular docking approaches. Int. J. Biol. Macromol. 2018, 107, 1414-1421. [CrossRef] [PubMed]

47. Dieleman, L.A.; Ridwan, B.U.; Tennyson, G.S.; Beagley, K.W.; Bucy, R.P.; Elson, C.O. Dextran sulfate sodium-induced colitis occurs in severe combined immunodeficient mice. Gastroenterology 1994, 107, 1643-1652. [CrossRef] 
48. Shin, E.S.; Hwang, H.J.; Kim, I.H.; Nam, T.J. A glycoprotein from Porphyra yezoensis produces anti-inflammatory effects in liposaccharide-stimulated macrophages via the TLR4 signaling pathway. Int. J. Mol. Med. 2011, 28, 809-815. [CrossRef]

49. Zenewicz, L.A.; Antov, A.; Flavell, R.A. CD4 T-cell differentiation and inflammatory bowel disease. Trends Mol. Med. 2009, 15, 199-207. [CrossRef]

50. Galvez, J. Role of Th17 cells in the pathogenesis of human IBD. ISRN Inflamm. 2014, 2014, 928461. [CrossRef]

51. Eeckhaut, V.; Van Immerseel, F.; Croubels, S.; De Baere, S.; Haesebrouck, F.; Ducatelle, R.; Louis, P.; Vandamme, P. Butyrate production in phylogenetically diverse Firmicutes isolated from the chicken caecum. Microb. Biotechnol. 2011, 4, 503-512. [CrossRef] [PubMed]

52. Hu, L.; Jin, L.; Xia, D.; Zhang, Q.; Ma, L.; Zheng, H.; Xu, T.; Chang, S.; Li, X.; Xun, Z.; et al. Nitrate ameliorates dextran sodium sulfate-induced colitis by regulating the homeostasis of the intestinal microbiota. Free Radic. Biol. Med. 2020, 152, 609-621. [CrossRef]

53. Vaziri, N.D.; Liu, S.M.; Lau, W.L.; Khazaeli, M.; Nazertehrani, S.; Farzaneh, S.H.; Kieffer, D.A.; Adams, S.H.; Martin, R.J. High amylose resistant starch diet ameliorates oxidative stress, inflammation, and progression of chronic kidney disease. PLoS ONE 2014, 9, e114881. [CrossRef]

54. Kim, D.H.; Sung, B.; Kang, Y.J.; Jang, J.Y.; Hwang, S.Y.; Lee, Y.; Kim, M.; Im, E.; Yoon, J.H.; Kim, C.M.; et al. Anti-inflammatory effects of betaine on AOM/DSSinduced colon tumorigenesis in ICR male mice. Int. J. Oncol. 2014, 45, 1250-1256. [CrossRef] [PubMed]

55. Vital, M.; Howe, A.C.; Tiedje, J.M. Revealing the bacterial butyrate synthesis pathways by analyzing (meta) genomic data. mBio 2014, 5, e00889. [CrossRef]

56. Furusawa, Y.; Obata, Y.; Fukuda, S.; Endo, T.A.; Nakato, G.; Takahashi, D.; Nakanishi, Y.; Uetake, C.; Kato, K.; Kato, T.; et al. Commensal microbe-derived butyrate induces the differentiation of colonic regulatory $\mathrm{T}$ cells. Nature 2013, 504, 446-450. [CrossRef] [PubMed]

57. Tatiya-aphiradee, N.; Chatuphonprasert, W.; Jarukamjorn, K. Oxidative stress exacerbates dextran sulfate sodium-induced ulcerative colitis in ICR mice. Biologia 2020. [CrossRef]

58. Crapo, J.D. Oxidative stress as an initiator of cytokine release and cell damage. Eur. Respir. J. 2003, 22, 4s-6s. [CrossRef]

59. Guan, G.; Lan, S. Implications of antioxidant systems in inflammatory bowel disease. BioMed Res. Int. 2018, 2018, 1290179. [CrossRef]

60. Toumpanakis, D.; Karatza, M.H.; Katsaounou, P.; Roussos, C.; Zakynthinos, S.; Papapetropoulos, A.; Vassilakopoulos, T. Antioxidant supplementation alters cytokine production from monocytes. J. Interferon. Cytokine Res. 2009, 29, 741-748. [CrossRef]

61. Chae, H.S.; Park, H.J.; Hwang, H.R.; Kwon, A.; Lim, W.H.; Yi, W.J.; Han, D.H.; Kim, Y.H.; Baek, J.H. The effect of antioxidants on the production of pro-inflammatory cytokines and orthodontic tooth movement. Mol. Cells 2011, 32, 189-196. [CrossRef] [PubMed]

62. Reimund, J.M.; Allison, A.C.; Muller, C.D.; Dumont, S.; Kenney, J.S.; Baumann, R.; Duclos, B.; Poindron, P. Antioxidants inhibit the in vitro production of inflammatory cytokines in Crohn's disease and ulcerative colitis. Eur. J. Clin. Investig. 1998, 28, 145-150. [CrossRef] [PubMed]

Publisher's Note: MDPI stays neutral with regard to jurisdictional claims in published maps and institutional affiliations.

(C) 2020 by the authors. Licensee MDPI, Basel, Switzerland. This article is an open access article distributed under the terms and conditions of the Creative Commons Attribution (CC BY) license (http://creativecommons.org/licenses/by/4.0/). 